Journal of Economics and Behavioral Studies

Vol. 6, No. 8, pp. 658-669, August 2014 (ISSN: 2220-6140)

\title{
Efficiency and Profitability of Tanzanian saving and Credit Cooperatives: Who is a Star?
}

\author{
*Nyankomo Marwa, Meshach Aziakpono \\ University of Stellenbosch Business School, South Africa \\ *nyankomo.marwa@gmail.com
}

\begin{abstract}
The objective of this paper is to evaluate and benchmark the performance of Tanzanian Saving and Credit Cooperatives (SACCOs). Measuring the performance of these organizations is useful in helping them to monitor and control their performance and business processes and improve productivity and profitability. The study used secondary data from audited financial statements from 103 SACCOs. Technical efficiency was estimated using the data envelopment analysis approach and profitability was measured using return on assets. Then an efficiency-profitability matrix was employed to distinguish best performers from struggling SACCOs. This particular approach has been selected to account for multiple dimensions of performance measures. Using the top $25 \%$ as a cut-off for profitability and efficiency we found that only $12 \%$ of the firms were diagnosed as best performers (stars). The majority of the firms (61\%) were classified under the low efficiency low profitability category. Fourteen SACCOs were highly profitable but had low efficiency scores, which demonstrate a potential for performance improvement by increasing their efficiency. Another group of 14 SACCOs were classified as potential candidates for divestiture because they had high efficiency scores but low profitability. Conclusively the performance of the industry in Tanzania needs a well-thought turnaround strategy to make it commercially viable. For the majority of the SACCO both profit-increasing and efficiencyincreasing strategies are required.
\end{abstract}

Keywords: Efficiency, Profitability, Saving and Credit Cooperatives, Tanzania

\section{Introduction}

During the past three decades, Tanzania has witnessed a surge in the growth of Savings and Credit Cooperatives (SACCOs). They have increased by 565\% in numbers between 2000 and 2012 (BOT, 2013). These institutions play an important role in economic growth and development by bridging the existing financing gap due to market failure in the mainstream financial market. To put it into context, in Tanzania about $90 \%$ of the population are excluded from the mainstream financial system (Finscope, 2009). Despite the significant role which SACCO might play in the economy, the performance and viability of the emerging industry remains unexplored. The smaller size and relatively risky operating environment of these institutions in terms of client composition and type of businesses supported may lead to an increased transaction costs. Higher transaction costs may affect the profitability, efficiency and sustainability of these institutions, which in turn might affect the overall viability of the industry. On the other side, since SACCO are member-owned and controlled mutual organizations, it might become easier to control the information asymmetry problem, lower the cost of screening and monitoring, and reduce transaction cost through peer pressure and monitoring (McKillop and Wilson, 2011). As a result, the combination of these factors may help to dampen the moral hazard problem, and instill an organizational culture which holds members accountable and prudential as to how they manage and use the financial resources. If this action dominates, then these organizations may become efficient and commercially viable. However which force may dominate remains an empirical question. Thus the objective of this paper is to evaluate and classify the performance of SACCOs in terms of their efficiency and profitability.

Specifically the study employs efficiency and profitability matrix to characterize the performance of SACCOs based on efficiency and profitability scores. The matrix linking the two performance dimensions is intended to capture the complex nature of organizational performance and help to develop the best performers (stars) and potential candidates for industry best practice. The findings from this study provide significant insights into performance management and policy strategies for managers, regulators and policy makers. Moreover, the study provides a contribution to the empirical literature about the performance of financial cooperatives 
in developing countries. This organized as follows: the next section presents the context of SACCOs in Tanzania, followed by literature review in section three. Section four presents the methodology. The results and conclusion are presented in sections five and six respectively.

Overview of the SACCO Industry in Tanzania: The provision of financial services to the poor has been a significant challenge for most developing countries for a long time. In case of Tanzania the problem has been further aggravated by the structural adjustment and privatization of state-owned enterprises including the financial sector. Prior to the 1980s the Tanzanian economy, including the financial sector, was centrally controlled (URT, 2002). However post 1980s the impact of privatization of the financial sector left more than $90 \%$ of the population excluded from mainstream banking. Recent statistics show that, despite an increasing number of commercial banks from five banks during 1990s to 44 banks in 2014, the percentage of exclusion from mainstream financial services remains at about $90 \%$ (Finscope, 2009). The financial exclusion situation is not unique to Tanzania: a similar trend can be traced across different countries, with sub-Saharan financial exclusion standing at around 88\% (MIX and CGAP, 2012). If we have to learn something from history, we can conclude that there is a market failure in the provision of financial services. The mainstream financial institutions in their current state, structures and operations are not well suited to serve the poor. In fact, there are several reasons both theoretically and practically which has been put forward to explain the existing market failure, including high transaction costs, high risk, information opacity, lack of collaterals, and inadequate infrastructure (Stiglitz \& Weiss, 1981; Luzzi \& Webber, 2006; Mwakajumilo, 2011; Marwa, 2014).

Despite the justification of the exclusion of the poor from the mainstream financial systems, the fact that this group constitutes the majority (about 90\%) calls for a new way of understanding and provision of financial services. During the past two decades there has been a significant growth in the microfinance movement as an alternative solution to the provision of financial services to the poor. The microfinance institutions developed an innovative and flexible lending model designed to address the challenges facing the provision of financial services to the poor. There are several variations of microfinance institutions currently operating in Tanzania, including NGO supported microfinances, international microfinance such as INCA and community based microfinance such as SACCOs. Of interest to this study is the fastest growth Saving and Credit Cooperatives, which have recorded an explosive growth in past decade. They grew 565\%, 585\% and 1781\% in numbers, memberships and savings volume respectively between 2000 and 2012 (BOT, 2013). While such growth may be a signal of a fast-growing industry which may be a game changer in financial sector, it may also be a signal for a highway to a financial crisis. This study intends to shed some light on the most likely outcome for the industry based on the current performance measures.

\section{Literature Review}

Definition of Profitability and Performance Evaluation Based on Profitability Analysis: Measuring profitability is the most important measure of the success of the business because a business that is not profitable cannot survive (Hofstrand, 2009).Profitability can be measured either from accounting perspectives or from economic perspectives. According to accounting perspectives, profit is measured as excess revenue over expenses for a transaction (Stickeny \& Weil, 2000; Edmonds, McNair, Millam \& Olds, 2000). In other words, the accounting definition of profit can be defined as net income gained for a given transaction. It can be further expressed as ratio of net income over financial revenue. Others studies have used more informative measures by using net income over assets, also known as return on assets (ROA). Depending on the objective of the research and the context, the net income to equity ratio is sometimes also used as a measure of profitability (Nyamsogoro, 2010). According to economic perspectives, profit is viewed as a net income after transactions plus the opportunity cost of the resources used to generate it (Bodie, Merton \& Cleeton, 2009). Since we are using the data from audited financial statements, it is difficult to implement economic profit because it can be challenging to quantify the opportunity cost of resources, therefore the accounting profit approach will be adopted.

Within the accounting approach we could use return on assets or return on equity or both. However, since some of the SACCOs are funded mainly by external loans and others are funded mainly by equity, this study will use return on assets as a measure of profitability to avoid overcompensating the SACCOs with favorable access to external financing. In theory, financial institutions including microfinance generate revenue from 
the loans, non-interest fees and other services such as insurance, money transmission, investing and factoring services (Nyamsogoro, 2010). Due to the nascent nature of the SACCO industry, the major sources of income come from interest income and non-interest income. Other services such as insurance, money transfer and money market investments are limited or virtually non-existent. From a management perspective, understanding the profitability patterns of SACCOs and microfinance is increasingly becoming an important endeavor since it is a crucial part of the sustainability equation of the industry. Also such information is important for industry regulators and shareholders for monitoring and evaluation of the industry performance.

Definition of Efficiency and Performance Evaluation: According to the classic definition, efficiency is the ability to produce the maximum output possible at given level of input (Coelli, Rao, O'Donnell \& Battese., 2005). It is measured as the ratio of output to input in a simple production setting. In a more general setting where multiple inputs and multiple outputs are concerned, then the efficiency becomes a scalar derived as a ratio of weighted sum of outputs and inputs (Vincent 1968 cited in Daraio and Simar, 2007; Lovell, 1993). The problem with a classic definition of efficiency is that, it fails to distinguish between efficiency and productivity which is also measured as a ratio between outputs and inputs (Daraio and Simar, 2007). In fact some authors have used the two concepts as synonymous without making any difference between the two (Sengupta, 1995; Cooper, Seiford and Tone, 2000). Daraio and Simar (2007) define efficiency as the distance between the quantity of inputs and outputs of a given firm compared to the distance of inputs and outputs for peer firms along the best possible frontier. The current study will adopt the Lovell (1993) definition of efficiency in which efficiency is defined as the difference between the observed inputs and outputs for a given firm as compared to optimal values of its inputs and outputs. In our case, since we have multiple inputs and outputs efficiency is defined as a ratio of weighted distance between outputs and inputs as compared to best practice frontier. The best practice frontier is constructed as a locus of the scalar of weighted inputs and outputs of the best performers.

According to theoretical and empirical literature, efficiency comes in different variations each capturing a specific dimension. These variations include technical efficiency, pure technical efficiency, scale efficiency, profit efficiency, cost efficiency, revenue efficiency, economic efficiency, and allocative efficiency (Coelli et al., 2005; Daraio and Simar, 2007). Despite variations in types of efficiency, they measure the performance of a firm using the extent to which it deviates from the best practice frontier given a specific dimension (cost, inputs, output or profit). Therefore the first step is to establish the best practice frontier using the high performing peer group and then compare all other firms' performance to the best practice. Once this is established the difference lies in whether the focus is on input minimization or output maximization which leads to technical efficiency. When the focus is on optimal scale of operation it leads to scale efficiency, whereas cost minimization leads to cost efficiency, profit maximization leads to profit efficiency, and optimal resource allocation based on the price of inputs leads to allocative efficiency. In some instance, both allocative efficiency and technical efficiency are evaluated, which leads to economic efficiency. Further details about different types of efficiency are presented in Coelli et al. (2005) and Daraio and Simar (2007).

The choice on the type of efficiency to be estimated is influenced by the objective of the study and the data availability. The existing empirical studies show a mixed application: some use just one variation of efficiency, some use combinations of two or more of the approaches but it is rare to find studies combining all the variations of efficiency dimensions. Given the fact that most of SACCOs are small and are managed by managers with limited experience, educational background and training, it is imperative to investigate the extent to which SACCOs are effective in transforming the assets and other inputs at their disposal into outputs. Thus this study focuses mainly on the technical and profitability ratio in a framework of efficiencyprofitability matrix (see the next section for details) to map profiles of the different emerging performance patterns in the SACCO industry. Technical efficiency has been selected based on the availability of data. Also, since it is a comprehensive measure of both scale and pure technical efficiency it captures both the effect of scale and management efficiency of the operation of each SACCO. Technical efficiency is estimated using Data Envelopment Analysis: this approach has been selected because of its flexibility in accommodating multiple input and multiple outputs (Coelli et al., 2005; Daraio and Simar, 2007; Zhu, 2014). More details about the estimation process of DEA are presented in methodology section. 
Performance Evaluation Based on Efficiency-Profitability Matrix: The literature on performance evaluation in the banking sector and other auxiliary financial service sector including microfinance is divided into three strands. The first strand of literature focuses on the application of financial ratios in analyzing the performance of financial institutions (Tucker \& Miles 2004; Yeh, 1996).The commonly used financial ratios include capital adequacy ratio, profitability ratio, assets utilization ratio and liquidity ratios (Yeh, 1996). Depending on the objective of the study and data availability some studies use different combination of ratios among the four sub-categories or just focus on return on assets and returns on equity. While this approach is useful in proving a snapshot of financial stability and profitability of financial institutions analyzed, it has been criticized for failing to capture the multiple dimension nature of financial institutions (Athanassopoulos \& Thanassoulis, 1995; Keramidou, Mimis and Fotinopoulou, 2013). As a result, most of the recent studies have focused on using a weighted index performance measure using data envelopment analysis. This strand of literature argues that most of the financial institutions use multiple inputs to produce multiple outputs. Therefore, a comprehensive approach which account for the multi-dimensionality nature of the inputs and outputs is important for a more realistic measure of performance. This has led to increasing popularity of data envelopment analysis in performance evaluation of the banking sector in the past three decades. However, most of the studies taking this route have focused on technical efficiency and scale efficiency (Ho \& Zhu, 2004; Aikaeli, 2008; Kamau, 2011; Moffat, 2008; Eken and Kale, 2011), while some of them have focused on cost efficiency (Casu, 2002; Berger and Humphrey, 1997). Another emerging strand of literature argues that standard measures of banking performance based on profitability ratios capture only one dimension of the performance which may be different from efficiency (Athanassopoulos \& Thanassoulis, 1995; Kumar, 2008; Frimpong, 2010; Keramidou, Mimis \& Fotinpoulou, 2013). They further argue that, while efficiency captures the multiple dimension nature of the financial institutions, it does not capture all the factors which are important in the performance of financial institutions.

A third strand of literature argues conclusively that the performance of financial institution is far more complex, which make it difficult to capture it using a single approach. As a solution, the literature proposes using the efficiency-profitability matrix developed by Boussofianne, Dyson \& Thanassoulius (1991) to combine efficiency and profitability. This approach offers a more comprehensive assessment of the performance of financial institutions. The approach has been applied by some empirical researchers in evaluating the performance of banking sector in Portugal, Cyprus, Ghana (Camanho \& Dyson, 1999), Soteriou and Zenios, 1999) and (Frimpong, 2010). The proposed efficiency-profitability matrix provides an important and useful tool for analyzing and categorizing the best performers as "Stars" in the efficiency-profitability space. Furthermore, the matrix identifies potential candidates whose efficiency and/or profitability needs to be improved as well as candidates for divestiture. The matrix is divided into four quadrants as illustrated by Figure 1below. The first quadrant represents firms whose profitability is high but efficiency is low. These firms are also called "Sleepers" implying that they are not exploiting their full potential: they could become even more profitable by increasing efficiency. The second quadrant represents the best performers: these firms are characterized by a high level of efficiency and a high level of profitability. This group of firms provides good candidates for performance benchmarking and developing industrial best practice which takes into account the local context and operating environment.

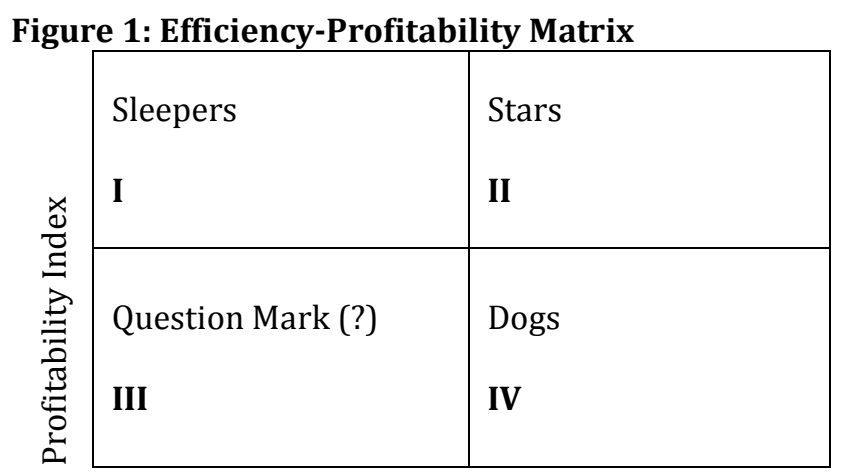

Efficiency Index

Source: Adapted from Camanho and Dyson, 1999 
The third quadrant (question mark) represents firms with low efficiency and low profitability. These are potential candidates for further growth and improvement; they may wish to borrow some of the good practices from the firms located in quadrant II (stars). It is important to acknowledge that the performance of an organization is complex and is influenced by several factors, some of which the efficiency and profitability index may not be able to capture. Therefore a detailed institutional investigation might be required to uncover the key challenges facing a specific organization. Despite such challenges, an organization in quadrant III may move into quadrant I, quadrant II or quadrant IV. Any quadrant apart from quadrant II is economically pares to inferior. In other words if a firm graduates into any other quadrant than quadrant II it is still under-utilizing its potential for further improvement. Therefore the mangers, policy makers and regulators are supposed to help the firms in all other quadrants to move towards quadrant II. This requires striking a balance between improved efficiency and profitability.

Firms in the fourth quadrant are termed "dogs". These firms have high efficiency but a low profitability level. Such behavior could be explained by an unfavorable operating environment, such as a high level of competition or low business potential catchment areas (Camanho \& Dyson, 1999). These firms are good candidates for divestiture or strategic turnaround of their business model and operations. A long-term policy to increase business potential, including public investments in institutions such as schools and colleges, may also be possible solutions to revitalize the business potential. The major challenge of using the efficiencyprofitability matrix framework for comprehensive evaluation of the performance of financial institutions lies in setting the boundaries (Athanassopoulos \& Thanassoulis, 1995). The precise boundary position between quadrants has remained subjective. For example Frimpong (2010) and Soteriou and Zenios (1999) used the arithmetic average of the efficiency index and profitability index, while Camanho and Dyson (1999) used a subjective boundary which is more skewed towards the top $10 \%$ of the efficiency score and about the top $25 \%$ of the profitability score. The current studies used the top $25 \%$ in both efficiency and profitability indices as the cut-off point. Since our efficiency data were skewed to the left, the choice of the cut-off was selected to avoid over-representation of the poor performers in the star quadrants which may have a dilution effect on the value of best practices to be derived from the benchmarks.

\section{Methodology}

Profitability Estimation: The profitability ratio has been estimated using the return on assets ratio (ROA). According to Joo, Nixon and Cook (2011) ROA is the most popular profitability ratio which is used for relative comparison within a firm over time or across firms. It is a more comprehensive measure than return on equity because it captures the overall performance of the institution's intermediations of total loanable funds including borrowed funds. In the case of saving and credit cooperatives this measure is useful because it captures both shareholders equity and funds borrowed from other sources such as pension funds. The ROA is estimated as demonstrated in Equation 1 below:

Return on Assets $($ RoA $)=\frac{\text { Net Income }}{\text { Total Assets }}$

Efficiency Estimation: The linear programming approach was used to estimate efficiency within the Data Envelopment Approach (DEA). DEA is a mathematical model developed by Charnels, Cooper and Rhodes (1978) and was used in the analysis for technical efficiency estimation under constant returns, and the model developed by Banker, Charnes and Cooper (1984) was used to estimate efficiency under variable returns to scale. As discussed in sections 2.2 and 2.3, DEA provides a flexible framework for estimating efficiency scores using multiple inputs and outputs for each firm or decision making unit (DMU). The resulting efficiency scores are then used in comparative analysis or benchmarking across firms in the same industry (Joo et al., 2011; Coelli et al., 2005). The mathematical formulation of efficiency estimation using DEA is presented in Equation 2 below.

$$
\begin{aligned}
& \operatorname{Max}_{\mu, v}\left(\frac{u^{\prime} q_{i}}{v^{\prime} x_{i}}\right) \\
& \text { Subject to } \frac{u^{\prime} q_{i}}{v^{\prime} x_{i}} \leq 1 ; \quad v, u \geq 0 ; \mathrm{j}=1,2, \ldots \mathrm{I}
\end{aligned}
$$


Where $u$ is $M^{*} 1$ vector of output weights and $V$ is a $N^{*} 1$ vector of inputs weights. The optimal weight of $v$ and $\mathrm{u}$ are obtained by solving Equation 2 above such that the efficiency of each SACCO is maximized, subject to constraints that all efficiency measures must be less than or equal to one. One particular problem of such a formulation is that it has an infinite number of solutions (Coelli et al., 2005). To avoid this, one can impose the constraint $v^{\prime} x=1$ which provides the following alternative formulation:

$$
\operatorname{Max}_{u, v}\left(u^{\prime} q_{i}\right) \text { Subject to: }\left\{\begin{array}{l}
v^{\prime} x_{i}=1 \\
u^{\prime} q_{j}-v^{\prime} x_{j} \leq 0 \quad \mathrm{j}=1,2 \ldots \ldots, \mathrm{I} \\
u, v \geq 0
\end{array}\right.
$$

The primal (multipliers) formulation stated above is cumbersome to solve numerically; the alternative dual formulation is more mathematically tractable. Therefore, the dual formulation which will be used in the analysis is presented as a minimization problem as follows.

$$
\operatorname{Min}_{(\theta, \lambda)} \theta \text { subject to }\left\{\begin{array}{l}
-q_{i}+Q \lambda \geq 0 \\
\theta x_{i}-X \lambda \leq 0 \\
\lambda \geq 0
\end{array}\right.
$$

Where $\theta$ is efficiency score; $\mathrm{q}$ is column vector of output, $\mathrm{Q}$ is MxI output matrix; $\mathrm{x}$ is column vector of inputs; $\mathrm{X}$ is NxI input matrixfor all DMUs and $\lambda$ is a vector of weighting coefficients.

The value of $\theta$ computed is the efficiency score for the corresponding DMU. It ranges between 0 and 1 with a value of 1 indicating a point on the efficiency frontier and hence a technically efficient DMU. All efficient firms will be connected by a continuous locus to form an efficient frontier. Every DMU efficient score will be compared to far it deviates from the frontier. The current study adopted an input-oriented approach as suggested by Coelli et al.(2005).This approach is dictated by what dimension the management has most control of and the policy question being asked. Since managers of SACCOs have more control over the inputs than outputs, we adopted an input-oriented approach. The intermediation approach was used in selecting input and outputs because of the intermediation orientation of saving and credit cooperatives. All the estimation procedures were done using STATA 11 software.

Efficiency and Profitability Matrix Construction: The efficiency-profitability matrix was constructed using the top 25 best performers using both technical efficiency and profitability ratios. The technical efficiency ratio was preferred to scale efficiency because it is a more comprehensive measure of both pure technical and scale efficiency. The resulting matrix was used to identify the firms in each corresponding category.

Super Star: Another strict set of performers called "super stars" was developed. A super star was classified as the top $25 \%$ in technical efficiency, pure technical efficiency, scale efficiency and profitability.

Data Sources: The study used data from 103 SACCOs reported in their audited financial statements during 2011.All the data used were for the year 2011 because that is the year which had the most recent SACCO data for the regions visited during January-March 2013ㄹ. Four regions of Tanzania (Dar Es Salaam, Arusha, Kilimanjaro and Mwanza) were included in the study. The regions were selected based on the highest

${ }^{1}$ Initially the study intended to collect the data from 300 SACCOs but after starting actual field work it was realised that there is no central pool of SACCO data country-wide. The researcher had to visit regional offices for Cooperatives and Auditing and Supervisory Cooperation to collect the audited financial statements. The excise was tedious and required a lot of follow-up and reminders. We managed to collect all available information on audited financial statements for the four regions. The study used only audited financial statements for consistency, and data from SACCOs without audited financial statements would be even more challenging to collect given the time and resource constraints, and spatial geographical distributions of these institutions. 
concentration of SACCOs with audited financial statements with the guidance of industry experts in Tanzania. The auditing was done by Tanzania Cooperative Audit and Supervisory Corporation (COASCO). The variables which were extracted from financial statements were: total cost in Tanzanian Shillings (TZS), total fixed assets in TZS (a proxy for capital), total deposit in TZS, and total loan portfolio in TZS. According to the intermediation approach input variables were total deposit, total fixed assets and total expenditure, and output variables were total revenue and total loans. Detailed literature and discussion on input and output selection has been presented in another paper which focuses entirely on efficiency measurement (Marwa, 2014).

\section{Results and Discussion}

Profitability and Efficiency Results of All SACCOs, Top 25\% and Super Stars: Profitability was measured using return on assets. Efficiency was estimated using technical efficiency. Further decomposition of technical efficiency into pure technical efficiency and scale efficiency for each SACCO was done using variable return to scale option. More detailed results on individual SACCOs is presented in Table A1 in the Appendix. The aggregate results have been categorized into three groups: all SACCOs, top $25 \%$ high performing SACCOs and super star SACCOs. All SACCO results report the overall average performance of SACCOs with respect to profitability and efficiency measures. Super stars are SACCOs whose performance is among the top 25\% in profitability, technical efficiency, pure technical efficiency and scale efficiency. The presence of technical inefficiency may be due to excessive utilization of inputs (too much wastage) or operating below or above the optimal scale of operation. Pure technical efficiency measures the former dimension while scale efficiency measures the latter. Similar results are presented for the top 25\% high performing SACCOs in each of the four measures (ROA, TE, PTE, and SCALE). The super star in this paper is defined as a SACCO whose scores in all four measures are among the top $25 \%$. In other words they are consistently among the best performers in all the dimensions of performance measures considered in this study. The average estimate for return on assets, technical efficiency, pure technical efficiency and scale efficiency for all the three categories of SACCOs are presented in Table 1below.

Table 1: Efficiency and Profitability Results for Super Star, Top 25\% and All SACCOs

\begin{tabular}{|c|c|c|c|c|c|c|}
\hline Variable & $\begin{array}{l}\text { Overall } \\
\text { mean } \\
(\mathrm{N}=103)\end{array}$ & $\begin{array}{l}\text { Top } \quad 25 \% \\
\text { Mean }(n=26)\end{array}$ & $\begin{array}{l}\text { Super Star } \\
\text { Mean }(n=4)\end{array}$ & $\begin{array}{lr}\text { Mean } & \text { difference } \\
\text { (Super } & \text { Star- } \\
\text { Overall) } \% & \\
\end{array}$ & $\begin{array}{l}\text { Mean difference } \\
\text { Star -Top25) \% }\end{array}$ & (Super \\
\hline RoA & 0.06 & 0.22 & 0.34 & $467 \%$ & $55 \%$ & \\
\hline TE & 0.42 & 0.85 & 1 & $138 \%$ & $18 \%$ & \\
\hline PTE & 0.58 & 1 & 1 & $72 \%$ & $0 \%$ & \\
\hline SCALE & 0.76 & 0.99 & 1 & $32 \%$ & $1 \%$ & \\
\hline
\end{tabular}

Based on our data, the average returns on asset (ROA)was $6 \%, 22 \%$ and $34 \%$ for all SACCOs, top $25 \%$ and super star respectively. The reported ROA is relatively high compared to the international benchmark $3 \%$ ROA for best practice in microfinance (ACCION, 2004). In fact the ROA in our study is higher than the 3\% return on assets reported in the commercial bank sector in east Africa region by EIB (2013). When comparing ROA figures across the sub-groups, super stars have the highest ROA (34\%) compared to the overall average $(6 \%)$ and $(22 \%)$ for overall average and top $25 \%$ respectively. The percentage difference among overall average, top $25 \%$ and super stars are $467 \%$ and55\%respectively. Thus ROA is the most dominant factor that distinguishes stars from non-stars. Another important variable is technical efficiency (TE) followed by pure technical efficiency (PTE), with the percentage difference from super star, overall average and top $25 \%$ being $138 \%, 18 \%$ and $72 \%, 0 \%$ for TE and PTE respectively. Scale efficiency seems to have the least impact as a distinguishing factor with about $32 \%$ difference among the overall average and super star. This can be explained by the fact that on average most of the scale efficiency of SACCOs was relatively high compared to other dimensions of efficiency. This is demonstrated clearly in Figure 2. When looking across difference performance measures, the discrepancy among the three categories (all firms, top 25\% and super stars) is sharper in return on assets and technical efficiency. The implication from these results is that technical 
efficiency and return on assets may have an important role in classifying SACCOs into top performers, stars and non-stars.

Figure 2: Return on Assets, Technical, Pure Technical and Scale Efficiency of all SACCOs, top 25\% and Super Stars.

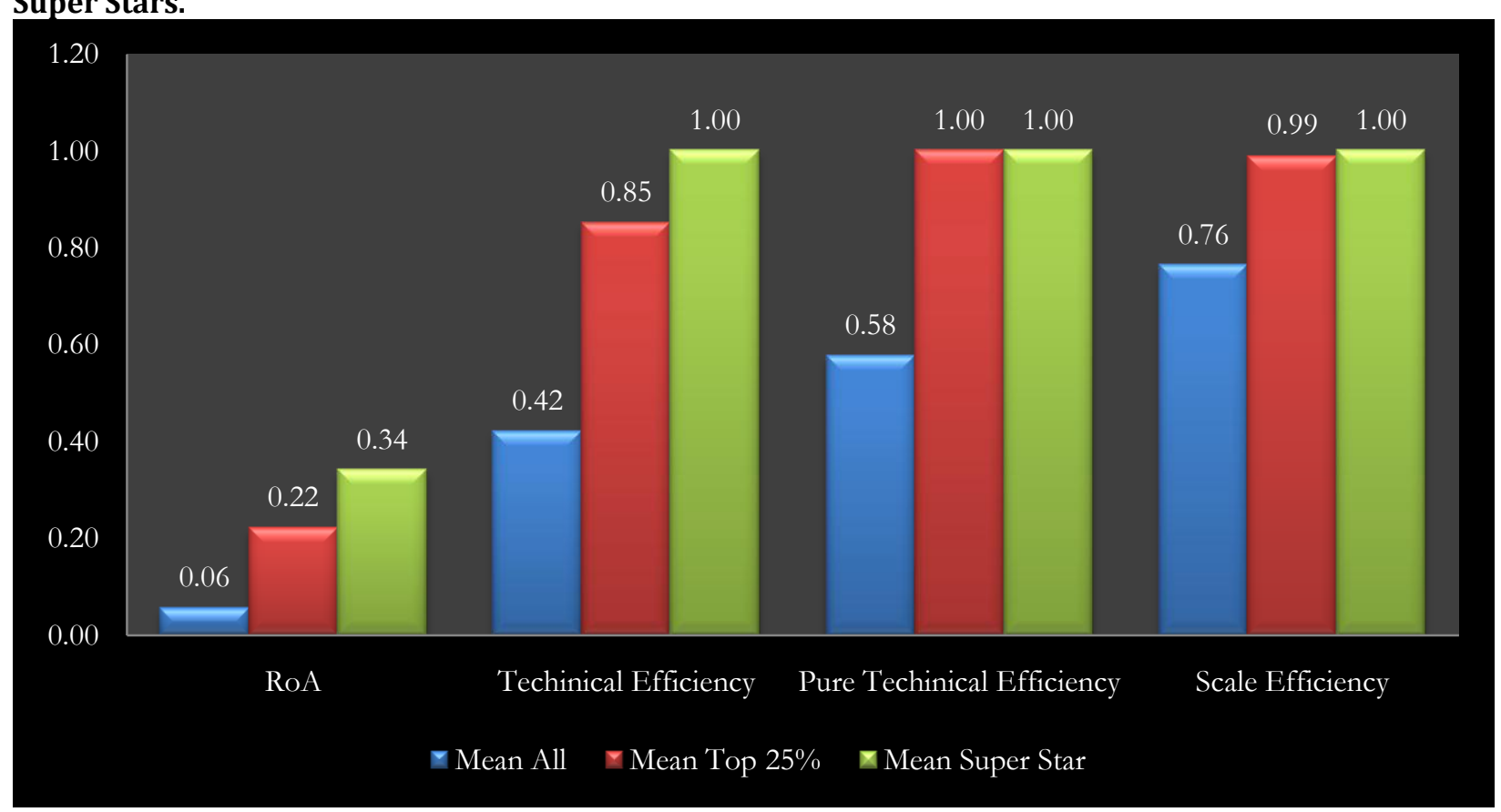

Efficiency-Profitability Matrix Classification: The classification results are demonstrated in Figure 3 and presented in detail instable 2. Only 12 out of 103 SACCOs were found to be among the top $25 \%$ performer in both technical efficiency and profitability dimensions. These SACCOs are the industry leaders and can be used to develop the industry best practices.

Figure 3: The Distribution of SACCOs among the four quadrants

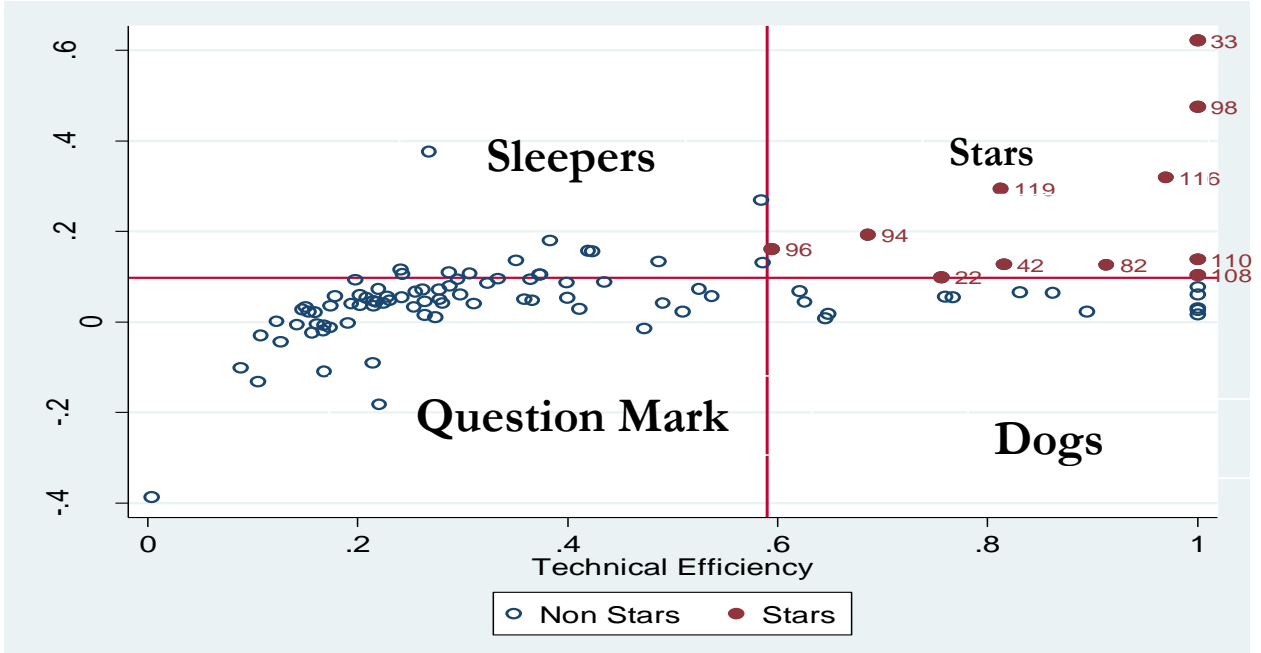

Most of the SACCOs (61\%) fall under the question mark quadrant, which implies that they perform below $25 \%$ in both dimensions. There is potential for improving the performance of this group by designing effective strategies to improve both efficiency and profitability. Such strategies may include reducing the wastage of resources during the intermediation process and other profit management strategies. 
Table 2: Efficiency-Profitability Classification of SACCOs

\begin{tabular}{llll}
\hline Quadrant & Classification & Frequency & Percentage \\
\hline I & Sleepers & 14 & $14 \%$ \\
II & Stars & 12 & $12 \%$ \\
III & Question Mark & 63 & $61 \%$ \\
IV & Dogs & 14 & $14 \%$ \\
\hline
\end{tabular}

About 14 other SACCOs were classified as sleepers: they are among the top 25\% in terms of profitability but they lag behind in the efficiency dimension. A closer look to this group reveals that on average they have high average loan portfolios compared to SACCOs in the other quadrants. The scale effect might explain high profit but low efficiency. There is a significant potential to increase the performance of these organizations by reducing the wastage of resources along the intermediation process. Another group of 14 of SACCOs was found to have high efficiency but low profit. These firms might be experiencing stiff competitive pressure or be in a low business catchment zone. They may be good candidates for divestiture or merging with other firms in quadrant II. A further attempt was made to identify the super stars. These are SACCOs whose performance in technical efficiency, pure technical efficiency, scale efficiency and profitability were among the top 25\%. As can be seen in Figure 4below, only four SACCOs met these criteria with two doing so at the margin $(110,108)$. When using the top $25 \%$ as a cut-off based on technical efficiency and ROA, 12 firms qualified as industry best practices. The SACCOs operating in other quadrants may try to understand and emulate the practices of this group. This result offers important inputs for future in-depth field studies for selected case studies in each quadrant. Such investigation will offer more insights into the internal challenges and dynamics in each group and possible ways forward.

Figure 4: Efficiency-Profitability Classification Matrix

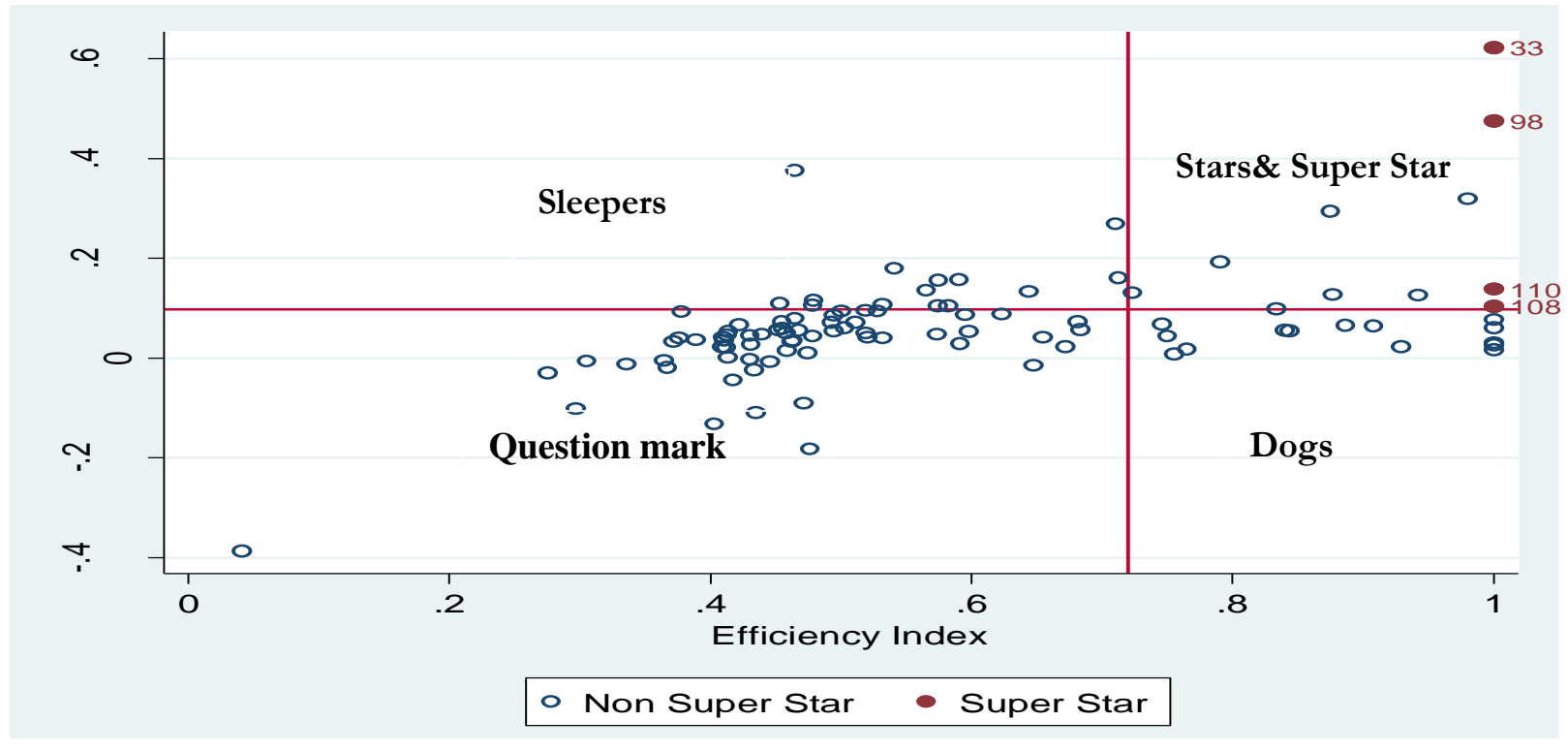

\section{Conclusion and Recommendations}

The objective of the current study was to evaluateand benchmarkthe performance of SACCOs in Tanzania based on efficiency and profitability measures.We developed a classification matrix based on four categories:one category comprised the best performers in both dimensions while the other three categories comprised underperformers in different dimensions. The underperformers included those firms struggling in both dimensions and those which struggle in either the efficiency dimension or the profitability dimension. Such a classification tool provides important information for monitoring, evaluation and improving the performance and profitability of organizations, andsuch evidenceis useful in guiding policy makers, regulators and managers in steering the industry in the right direction. Our results reveals curious classification patterns.About $61 \%$ of the SACCOs are classified as underperforming in both efficiency and 
profitability dimensions. These groups need an urgent turn around strategy which focuses on improving wastage reduction duringthe intermediation process and increasing profitability. Another group of firms $(28 \%)$ is required to improve either their profitability or efficiency strategy depending whether they are in quadrant IV or I respectively. Only $12 \%$ of the SACCOs were classified as best performers. These could be used for the development industry best practice for struggling firms to learn from.Weacknowledge that it may be unrealistic to expectabout $25 \%$ or 26 SACCOs to be among the top performers based on $25 \%$ the cutoff,but $12 \%$ of SACCOs out of $25 \%$ is definatelya sign ofpoor performancein the industry.

The observed poor performance in the industry is more worrying given the fact that the SACCOs included in the study are likely to be among the top performers in their own region. This implies that an urgent turnaround strategy is required in the industry. Learning the best practices from the best performers in the country and elsewhere may offer some useful insights to struggling SACCOs. These findings show important insights for the regulators, academia, and managers of the SACCOs. From the perspective of regulators, a close watch and monitoring of the industry is required. This should be complemented with a supporting enviroment in nurturing and steering the industry in the right direction. Such action is important given the recent surge in growth of this industry and the recorded poor performance which may signal a future performance crisis. Managers and shareholders need to focus their attention on increasing efficency during the intermediation process through cost-cutting and increasing profitability. From the academic front, more empirical research focusing on performance evaluation over time andunderstanding the drivers of the performance is needed. The current study was limited to audited financial statements available during 2011:this was the most recent and more comprehensive data available during the time of the research (2013). We acknowledge that this may lead to a bias in our estimates since we did not include SACCOs with non-audited financial statements, andthis group of SACCOs may have different performance trajectories than the ones which reported their information. Therefore future studies may consider doing a comparative analysis of the performance between audited and non-audited SACCOs. Finally, the current research could be replicated by increasing the sample size.

Acknowldgement: We acknowlge the funding support from REPOA and African Economic Research Consortium . We also appreciate the commentsfrom the editor and two anonymous reviewers who helped to point out areas for imporement for the earlier version of this paper.

\section{References}

ACCION. (2004). Optimal Range for Return on Asset. ACCA_CGA_CPA. pdf. http://www.mixmarket.org/sites/default/files/medialibrary/20501.701/ACF_rating_report_final.pd f Accessed 2 September 2013.

Aikaeli, J. (2008). Commercial Banks Efficiency in Tanzania. A paper presented at a CSAE Conference on Economic Development in Africa, held at St. Catherine's College, Oxford, March 16-18.

Athanassopoulos, A. D. \& Thanassoulis, E. (1995). Separating Market Efficiency from Profitability and Its Implications for Planning. The Journal of the Operational Research Society, 46(1), 20-34.

Berger, A. N. \& Humphrey, D. B. (1997). Efficiency of financial institutions: International survey and directions for future research. European Journal of Operational Research, 98(2), 175-212.

Bodie, Z., Merton, R. C. \& Cleeton, D. L. (2009). Financial Economics (2nd ed). London: Pearson Education International.

BOT. (2013).Bank of Tanzania, online resources on Microfinance. Available online at http://www.bottz.org/MFI/ (Accessed 25 November, 2013).

Boussofiane, A., Dyson, R. G. \& Thanassoulis, E. (1991).Applied Data Envelopment Analysis. European Journal of Operational Research, 52(1), 1-15.

Camanho, A. S. \& Dyson, R. G. (1999).Efficiency, size, benchmarks and targets for bank branches: an application of data envelopment. Journal of the Operational Research Society, 50(9), 903.

Casu, B. (2002). A Comparative Study of the Cost Efficiency of Italian Bank Conglomerates. Managerial Finance, 28(2), 3-23.

Charnes, A., Cooper, W. W. \& Rhodes, E. (1978).Measuring Efficiency of Decision Making Units. European Journal of Operational Research, 2(6), 429-444.

Coelli, T. J., Rao, D. S. P., O’Donnell, C. J. \& Battese, G. E. (2005). An Introduction to Efficiency and Productivity Analysis. New York: Spring Science and Business Media. 
Cooper, W. W., Seiford, L. M. \& Tone, K. (2000). Data Envelopment Analysis: A Comprehensive Text with Models, Applications, References and DEA-Solver Software. Boston: Kluwer Academic Publishers.

Banker, R. D., Charnes, A. \& Cooper, W. W. (1984). Some Models for Estimating Technical and Scale Efficiencies in Data Envelope Analysis. Management Science, 30(9), 1078-1092.

Daraio, C. \& Simar, L. (2007). Advanced Robust and Nonparametric Methods in Efficiency Analysis Methodology and Applications. Springer, New York, USA

Edmonds, T. P., McNair, F. M., Millam, E. E. \& Olds, P. R. (2000). Fundamental Financial Accounting Concepts (3rd ed). Boston: McGraw-Hill Companies Inc.

EIB. (2013). Banking in sub-Saharan Africa Challenges and Opportunities. European Investment Bank Report.

Eken, M. H. \& Kale, S. (2011). Measuring bank branch performance using Data Envelopment Analysis: The case of Turkish bank branches. African Journal of Business Management, 5, 889-901.

Finscope. (2009). National Survey on Access to and Demand for Financial Services in Tanzania. Available online at http://dgroups.org/DisplayKnowledge.aspx?c=1e6c2b52-50f6-457d-b533- bb0b2ccbe7ee $\& \mathrm{f}=\mathrm{db} 63 \mathrm{cb} 15-4 \mathrm{e} 27-4 \mathrm{~d} 7 \mathrm{f}-916 \mathrm{f}-5318 \mathrm{a} 97 \mathrm{db} 7 \mathrm{e} 3 \& \mathrm{i}=03 \mathrm{c} 763 \mathrm{a} 2-\mathrm{ea50}-4 \mathrm{f} 1 \mathrm{f}-82 \mathrm{~d} 7-\quad$ 73dd1b0ab5d2 (Accessed 25 July, 2012).

Frimpong, J. S. (2010). Investigating Efficiency of Ghana Banks: A Non-Parametric Approach. American Journal of Scientific Research, 7, 64-76.

Ho, C. T. \& Zhu, D. S. (2004). Performance measurement of Taiwan's commercial banks. International Journal of Productivity and Performance Management, 53(5), 425-433.

Hofstrand, D. (2009). Understanding Profitability. Ag Decisions Makers, 2, C3-24.

Joo, S. J., Nixon, D. \& Stoeberl, P. A. (2011).Benchmarking with data envelopment analysis: a return on asset perspective. Benchmarking: An International Journal, 18(4), 529-542.

Kamau, A. W. (2011). Intermediation efficiency and productivity of the banking sector in Kenya. Interdisciplinary Journal of Research in Business, 1(9), 12-26.

Keramidou, I., Mimis, A., Fotinopoulou, A. \& Tassis, C. D. (2013). Exploring the relationship between efficiency and profitability. Benchmarking: An International Journal, 20(5), 647-660.

Kumar, S. (2008).An Analysis of Efficiency - Profitability Relationship in Indian Public Sector Banks. Global Business Review, 9(1), 115-129.

Lovell, C. A. K. (1993). Production Frontiers and Productive Efficiency. In H.O. Fried, C.A.K. Lovell \&S.S. Schmidt (Eds.), The Measurement of Productive Efficiency. New York: Oxford University Press.

Luzzi, G. F. \& Webber, S. (2006). Measuring Performance of Microfinance Institutions. Cahier No HESSO/HEG-ge/c-06/1/3-CH.

Marwa, N. (2014). Micro, Small and Medium Enterprises' External Financing Challenges: The Role of Formal Financial Institutions and Development Finance Intervention in Tanzania. International Journal of Trade, Economics and Finance, 5(3), 230-234.

McKillop, D. \& Wilson, J. O. S. (2011).Credit Unions: A Theoretical and Empirical Overview. Journal of Financial Markets, Institutions \& Instruments, 20(3), 79-123.

MIX and CGAP. (2012). 2011 Sub-Saharan Africa Regional Snapshot.MIX and CGAP Analysis of Key Trends. Accessed online at http://opportunity.org/content/News/Publications/Knowledge\%20Exchange /2011\%20Sub-Saharan\%20Africa\%20Regional\%20Snapshot.pdf (Accessed 26 June, 2014).

Moffat, B. D. (2008). Efficiency and productivity in Botswana's Financial Institutions, PhD Thesis presented at University of Wollongong.

Mwakajumilo, S. L. I. (2011). The role of informal microfinance institutions in saving mobilization, investment and poverty reduction. A case of savings and credit cooperative societies (Saccos) in Tanzania from 1961-2008.PhD thesis, St. Clements University, Turks and Caicos Islands of British West Indies.

Nyamsogoro, G. D. (2010). Financial Sustainability of Rural Microfinance in Tanzania. PhD thesis, University of Greenwich, UK.

Sengupta, J. K. (1995). Dynamics of Data Envelopment Analysis. Theory of Systems Efficiency. Dordrecht: Kluwer Academic Publishers.

Soteriou A. \& Zenios S. A. (1999). Operations, quality, and profitability in the provision of banking services. Management Science, 45(9), 1221-38.

Stickney, C. P. \& Weil, R. L. (2000). Financial Accounting: An Introduction to Concepts, Methods, and Uses (9th ed). USA: The Dryden Press.

Stiglitz, J. \& Weiss, A. (1981).Credit rationing in markets with incomplete information. American Economic Review, 71(2), 393-409. 
Tucker, M. \& Miles, G. (2004). Financial Performance of Microfinance Institutions: A Comparison to Performance of Regional Commercial Banks by Geographic Region. Journal of Microfinance, 6(1), 41-54.

URT. (2002).Cooperative Development Policy. United Republic of Tanzania. Government Printers, Dar Es Salaam

Yeh, Q. J. (1996). Application of Data Envelopment Analysis in Conjunction with Financial Ratios for bank Performance Evaluation. Journal of Operation Research Society, 47, 980-988

Zhu, J. (2014). Quantitative Models for Performance Evaluation and Benchmarking: Data Envelopment Analysis with Spreadsheets (3rd ed). New York: Springer.

Table A1: Estimates for Technical Efficiency (TE), Pure Technical Efficiency (PTE), Scale Efficiency and Returns to Scale

\begin{tabular}{|c|c|c|c|c|c|c|c|c|c|c|c|c|c|}
\hline ID & Regio & TE & PTE & SCALE & RT & Ran & ID & Regi & TE & PTE & SCALE & RTS & Ran \\
\hline 33 & DSM & 1 & 1 & 1 & Crs & 1 & 20 & DSM & 0.3 & 0.3 & 0.87 & irs & 53 \\
\hline 13 & DSM & 1 & 1 & 1 & Crs & 2 & 12 & MWZ & 0.3 & 0.8 & 0.34 & $\mathrm{drs}$ & 54 \\
\hline 46 & DSM & 1 & 1 & 1 & Crs & 3 & 50 & DSM & 0.2 & 0.6 & 0.42 & drs & 55 \\
\hline 98 & AR & 1 & 1 & 1 & Crs & 3 & 12 & MWZ & $\begin{array}{l}0.2 \\
0.2\end{array}$ & 0.5 & 0.57 & drs & 56 \\
\hline 48 & DSM & 1 & 1 & 1 & Crs & 5 & 77 & KLM & 0.2 & 1 & 0.28 & irs & 57 \\
\hline 11 & MWZ & 1 & 1 & 1 & Crs & 5 & 43 & DSM & 0.2 & 0.4 & 0.69 & irs & 58 \\
\hline 10 & MWZ & 1 & 1 & 1 & Irs & 7 & 64 & DSM & 0.2 & 0.2 & 0.97 & $\mathrm{drs}$ & 59 \\
\hline 56 & DSM & 1 & 1 & 1 & Crs & 8 & 72 & KLM & 0.2 & 0.3 & 0.81 & irs & 60 \\
\hline 41 & DSM & 1 & 1 & 1 & Crs & 9 & 52 & DSM & 0.2 & 0.3 & 0.79 & irs & 61 \\
\hline 11 & MWZ & 0.9 & 1 & 0.97 & Irs & 10 & 10 & AR & 0.2 & 0.3 & 0.77 & drs & 62 \\
\hline 82 & $\mathrm{AR}$ & 0.9 & 1 & 0.91 & Drs & 11 & 19 & DSM & 0.2 & 0.4 & 0.54 & irs & 63 \\
\hline 10 & DSM & 0.8 & 0.97 & 0.93 & Drs & 12 & 79 & AR & 0.2 & 0.9 & 0.28 & $\begin{array}{l}\text { irs } \\
\text { irs }\end{array}$ & 64 \\
\hline 34 & DSM & 0.8 & 1 & 0.86 & Irs & 13 & 11 & MWZ & 0.2 & 0.5 & $\begin{array}{l}0.48 \\
0.49\end{array}$ & $\begin{array}{l}\text { irs } \\
\text { irs }\end{array}$ & 65 \\
\hline 53 & DSM & 0.8 & 0.83 & 1 & Irs & 14 & $\begin{array}{l}11 \\
69\end{array}$ & KLM & 0.2 & 0.3 & 0.82 & drs & 66 \\
\hline 42 & DSM & 0.8 & 1 & 0.82 & Irs & 15 & 93 & $A R$ & 0.2 & 0.2 & 0.93 & irs & 67 \\
\hline 11 & MWZ & 0.8 & 1 & 0.81 & Irs & 16 & 17 & DSM & 0.2 & 0.2 & 1 & $\begin{array}{l}\text { ins } \\
\text { irs }\end{array}$ & 68 \\
\hline 95 & AR & 0.7 & 0.83 & 0.95 & Irs & 17 & 26 & DSM & 0.2 & 0.2 & 0.94 & $\begin{array}{l}\text { irs } \\
\text { irs }\end{array}$ & 69 \\
\hline 84 & $\mathrm{AR}$ & 0.7 & 0.77 & 0.99 & Irs & 18 & 21 & DSM & 0.2 & 0.2 & 0.8 & irs & 70 \\
\hline 10 & $\mathrm{AR}$ & 0.7 & 1 & 0.76 & Irs & 19 & 14 & DSM & 0.2 & 0.2 & 0.93 & irs & 71 \\
\hline 22 & DSM & 0.7 & 0.8 & 0.94 & Irs & 20 & 76 & KLM & $\begin{array}{l}0.2 \\
0.2\end{array}$ & 0.3 & $\begin{array}{l}0.67 \\
0.67\end{array}$ & $\begin{array}{l}113 \\
\text { irs }\end{array}$ & 72 \\
\hline 94 & $\mathrm{AR}$ & 0.6 & 0.99 & 0.69 & Irs & 21 & 11 & DSM & 0.2 & 0.2 & 0.98 & irs & 73 \\
\hline 44 & DSM & 0.6 & 1 & 0.65 & Drs & 22 & 49 & DSM & 0.2 & 0.2 & 0.9 & drs & 74 \\
\hline 63 & DSM & 0.6 & 0.7 & 0.92 & Irs & 23 & 58 & DSM & 0.2 & 1 & 0.22 & irs & 75 \\
\hline 51 & DSM & 0.6 & 1 & 0.63 & Irs & 24 & 70 & KLM & 0.2 & 0.3 & 0.72 & $\begin{array}{l}\text { irs } \\
\text { ins }\end{array}$ & 76 \\
\hline 39 & DSM & 0.6 & 0.63 & 0.99 & Irs & 25 & 73 & KLM & 0.2 & 0.2 & 0.94 & irs & 77 \\
\hline 96 & AR & 0.5 & 0.81 & 0.74 & Irs & 26 & 68 & KLM & 0.2 & 0.2 & 0.98 & irs & 78 \\
\hline 65 & DSM & 0.5 & 1 & 0.59 & Drs & 27 & 10 & AR & 0.2 & 0.2 & 0.76 & irs & 79 \\
\hline 27 & DSM & 0.5 & 0.65 & 0.89 & Drs & 28 & 32 & DSM & 0.2 & 0.2 & 0.95 & $\begin{array}{l}\text { ins } \\
\text { ins }\end{array}$ & 80 \\
\hline 90 & AR & 0.5 & $\begin{array}{l}0.65 \\
0.57\end{array}$ & $\begin{array}{l}0.97 \\
0.94\end{array}$ & Irs & $\begin{array}{l}28 \\
29\end{array}$ & 38 & DSM & $\begin{array}{l}0.2 \\
0.2\end{array}$ & $\begin{array}{l}0.2 \\
0.3\end{array}$ & 0.66 & $\begin{array}{l}\text { irs } \\
\text { irs }\end{array}$ & 81 \\
\hline 47 & DSM & 0.5 & 0.53 & 0.98 & Drs & 30 & 35 & DSM & 0.2 & 0.6 & 0.32 & irs & 82 \\
\hline 60 & DSM & 0.5 & 0.51 & 1 & Drs & 31 & 11 & MWZ & 0.1 & 0.3 & 0.62 & irs & 83 \\
\hline 37 & DSM & 0.4 & 0.97 & 0.51 & Irs & 32 & 3 & DSM & 0.1 & 0.2 & 0.89 & $\begin{array}{l}\text { irs } \\
\text { irs }\end{array}$ & 84 \\
\hline 83 & AR & $\begin{array}{l}0.4 \\
0.4\end{array}$ & 0.53 & 0.91 & Irs & 33 & 71 & KLM & $\begin{array}{l}0.1 \\
0.1\end{array}$ & 0.1 & 1.09 & irs & $\begin{array}{l}84 \\
85\end{array}$ \\
\hline 59 & DSM & 0.4 & 0.48 & 0.99 & Irs & 34 & 36 & DSM & 0.1 & 0.2 & 0.85 & irs & 86 \\
\hline 9 & DSM & $\begin{array}{l}0.4 \\
0.4\end{array}$ & 1 & 0.43 & Irs & $\begin{array}{l}34 \\
35\end{array}$ & $\begin{array}{l}30 \\
10\end{array}$ & MWZ & $\begin{array}{l}0.1 \\
0.1\end{array}$ & 0.3 & 0.45 & $\begin{array}{l}\text { irs } \\
\text { irs }\end{array}$ & 87 \\
\hline 11 & MWZ & 0.4 & 0.64 & 0.67 & Irs & 36 & 25 & DSM & 0.1 & 0.1 & 1 & irs & 88 \\
\hline 87 & $A R$ & $\begin{array}{l}0.4 \\
0.4\end{array}$ & $\begin{array}{l}0.04 \\
0.48\end{array}$ & 0.87 & Irs & $\begin{array}{l}30 \\
37\end{array}$ & 91 & AR & $\begin{array}{l}0.1 \\
0.1\end{array}$ & $\begin{array}{l}0.1 \\
0.9\end{array}$ & 0.18 & irs & $\begin{array}{l}80 \\
89\end{array}$ \\
\hline 10 & $\mathrm{AR}$ & 0.4 & 0.45 & 0.91 & Irs & 38 & 18 & DSM & 0.1 & 0.2 & 0.69 & irs & 90 \\
\hline 15 & DSM & 0.4 & 0.4 & 0.99 & Irs & 39 & 85 & $\mathrm{AR}$ & 0.1 & 0.7 & 0.23 & irs & 91 \\
\hline 10 & MWZ & 0.4 & 0.41 & 0.98 & Irs & 40 & 86 & $\mathrm{AR}$ & 0.1 & 0.1 & 0.9 & irs & 92 \\
\hline 29 & DSM & 0.3 & $\begin{array}{l}0.78 \\
0.78\end{array}$ & 0.50 & Irs & 41 & 61 & DSM & $\begin{array}{l}0.1 \\
0.1\end{array}$ & $\begin{array}{l}0.1 \\
0.1\end{array}$ & 0.98 & irs & 93 \\
\hline 16 & DSM & 0.3 & 0.65 & 0.59 & Irs & 42 & 11 & MWZ & 0.1 & 0.1 & 0.9 & irs & 94 \\
\hline 10 & MWZ & 0.3 & 0.37 & 1 & Irs & 43 & 5 & DSM & 0.1 & 0.2 & 0.77 & irs & 95 \\
\hline 4 & DSM & 0.3 & 0.39 & 0.96 & Irs & 44 & 99 & $A R$ & 0.1 & 1 & 0.15 & irs & 96 \\
\hline 2 & DSM & 0.3 & 0.38 & 0.98 & Irs & 45 & 57 & DSM & $\begin{array}{l}0.1 \\
0.1\end{array}$ & 0.3 & 0.47 & $\begin{array}{l}\text { irs } \\
\text { irs }\end{array}$ & 97 \\
\hline 11 & MWZ & 0.3 & 0.52 & 0.7 & Irs & 46 & 74 & KLM & 0.1 & 1 & 0.13 & $\begin{array}{l}\text { irs } \\
\text { irs }\end{array}$ & 98 \\
\hline 23 & DSM & 0.3 & 0.6 & 0.6 & Drs & 47 & 75 & KLM & 0.1 & 01 & 0.99 & $\mathrm{drs}$ & 99 \\
\hline 81 & $\mathrm{AR}$ & 0.3 & 0.35 & 0.99 & Irs & 48 & 62 & DSM & 0.1 & 0.5 & 0.21 & irs & 100 \\
\hline $\begin{array}{l}01 \\
45\end{array}$ & DSM & 0.3 & 0.41 & 0.81 & Irs & $\begin{array}{l}40 \\
49\end{array}$ & 7 & DSM & $\begin{array}{l}0.1 \\
0.1\end{array}$ & 1 & 0.1 & $\begin{array}{l}\text { irs } \\
\text { irs }\end{array}$ & 101 \\
\hline 88 & $\mathrm{AR}$ & 0.3 & 0.47 & 0.69 & Irs & 50 & 55 & DSM & $\begin{array}{l}0.1 \\
0.0\end{array}$ & 0.1 & 0.67 & irs & 102 \\
\hline 80 & $A R$ & 0.3 & 0.32 & 0.96 & Irs & 51 & 12 & DSM & 0 & $\begin{array}{l}.1 \\
0.0\end{array}$ & 0.06 & $\begin{array}{l}\text { ins } \\
\text { irs }\end{array}$ & 103 \\
\hline 31 & DSM & 0.3 & 0.31 & 0.97 & Irs & 52 & & & & & & & \\
\hline
\end{tabular}

Note: AR (Arusha); MWZ (Mwanza); DSM (Dar Es Salaam); KLM (Kilimanjaro); ID (SACCOs'ID); TE (Technical Efficiency); PTE (Pure Technical Efficiency). 